\title{
A comparative study of personality disorder between demanding and no demanding divorce couples attending family counseling center in Sanandaj
}

\author{
Sina Valiee ${ }^{1}$, Shahram Sharifi ${ }^{2}$, Hajar Kashefi ${ }^{3}$, Farzaneh Khanpour $^{4}$ \\ 1-Associate Professor, Clinical Care Research Center, Kurdistan University of Medical Sciences, Sanandaj, Iran. \\ 2- Master of Science in Technology, Educational Assistant, Continuous Education, Kurdistan University of Medical \\ Sciences, Sanandaj, Iran. \\ 3- Student Research Committee, Kurdistan University of Medical Sciences, Sanandaj, Iran. \\ 4- MSc Clinical Psychology, Kurdistan University of Medical Sciences, Sanandaj, Iran (Corresponding Author). \\ E-mail: far.khanpour@gmail.com
}

Received: 07/01/2020

Accepted: 26/02/2020

\begin{abstract}
Introduction: Personality has a lasting effect on marital relationships and some personality traits increase tensions and conflicts among couples and these conflicts can threaten the continuation of marital life.
\end{abstract}

Aim: Considering the increasing divorce rate and the importance of personality disorder in this study, the aim of this study was to compare the level of personality disorder in couples applying for divorce referring to counseling centers and non-applicants for divorce in Sanandaj. The present research is a comparative study.

Method: The present study is a comparative study and the study population is the couples seeking and non-applying for divorce. 55 divorce applicants were selected through convenience sampling and 55 non-divorce applicants were selected by multistage cluster sampling in 2019and completed the Millon III questionnaire. Data were analyzed by SPSS 21 software using independent t-test and one-way ANOVA.

Results: The results of this study showed that among couples applying for divorce and divorced couples, disclosure, desirability, schizoid, distraction, depression, affiliated, demonstrative, selfish, negative, selfish, schizotypal, borderline, anxiety disorder, Depressed mood, post traumatic stress, thinking disorder, major depression and delusional disorder $(p<0.05)$. However, there are no significant differences in the scales of antisocial, anxiety, obsession, paranoid, pseudo-physical, manic, alcohol and drug dependence.

Conclusion: According to the results of the research, the significance of the most of the dimensions of personality disorder in divorce applicants and the high divorce rates in society, education and the creation of appropriate psychological treatments for increasing the knowledge and treatment of couples and reducing the divorce rate is necessary.

Keywords: Personality disorder, Divorce applicants, Non-divorced couples

\footnotetext{
How to cite this article : Valiee S, Sharifi Sh, Kashefi H, Khanpour F. A comparative study of personality disorder between demanding and no demanding divorce couples attending family counseling center in Sanandaj. Shenakht Journal of Psychology and Psychiatry. 2020; 7 (1): 15-29 . URL: http://shenakht.muk.ac.ir/article-1-765-fa.pdf

Copyright $\odot 2018$ the Author (s). Published by Kurdistan University of Medical Sciences. This is an open access article distributed under the terms of the Creative Commons Attribution-Non Commercial License 4.0 (CCBY-NC), where it is permissible to download, share, remix, transform, and buildup the work provided it is properly cited. The work cannot be used commercially without permission from the journal.
} 


\title{
بررسى مقايسهاى اختلالات شخصيت بين زوجين متقاضى طلاق مراجعه كننده به مراكز مشاور خانواده و زوجين غير متقاضى طلاق شهر سنندج
}

\author{
سينا وليئى '، شهرام شريفى ‘، هاجر كاشفى ‘ فرزانه خانيورع

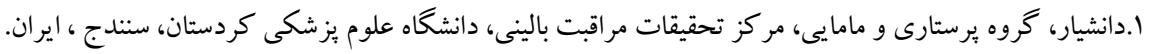

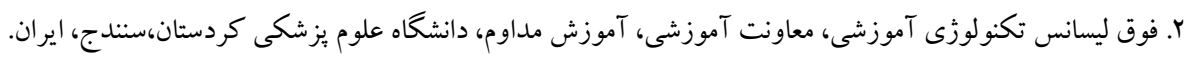

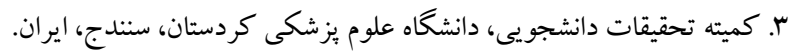

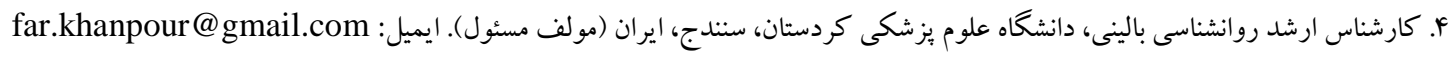

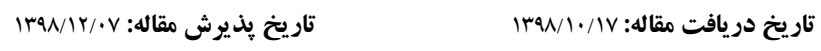

جكيده

مقدمه: شخصيت تأثيرات بايدارى بر روابط زناشويى دارد و برخى از ويز گىهاى شخصيتى تنشها و تعارضات را بين زوجين افزايش مى دهد.

هدف: يزوهش حاضر با هدف بررسى مقايسهاى ميزان اختلال شخصيت در زوجين متقاضى طلاق و زوجين غير متقاضيان طلاق شهرستان سنندج انجام شد.

روش: مطالعه حاضر على مقايسهاى بوده و جامعه مورد مطالعه زوجين متقاضى و غير متقاضى طلاق مىباشند. هه نفر متقاضى طلاق

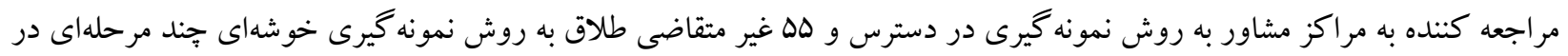

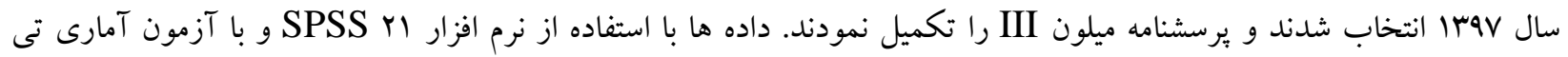
مستقل و آناليز واريانس يكك طرفه تجزيه و تحليل شد. يافتها: نتايج نشان داد كه در بين زوجين متقاضى طلاق و زوجين غير متقاضى طلاق مقياسهاى بدنمايى، افشاگرى، مطلوبيت،

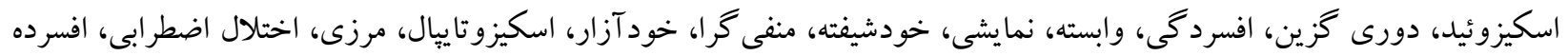

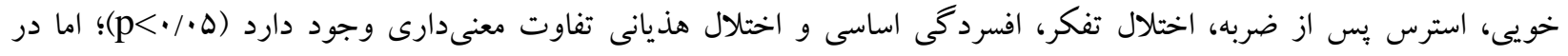

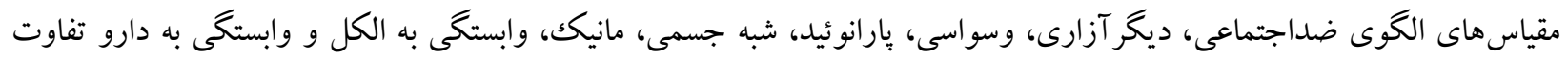
معنى دارى بين دو گروه وجود ندارد. نتيجه كيرى: با توجه به اهميت اختلال شخصيت در متقاضيان طلاق و بالا بودن آمار طلاق در جامعه، آموزش و نمايش روانشناختى براى بالا بردن آكاهى و كاهش آمار طلاق ضرورى مئنمايد. كليد وازهها: اختلال شخصيت، زوجين متقاضى طلاق، زوجين غير متقاضى طلاق 
آمارها نشان مى دهند كه تعداد طلاق در سال هاى اخير

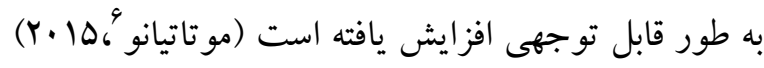

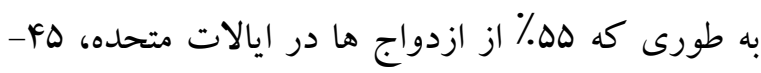

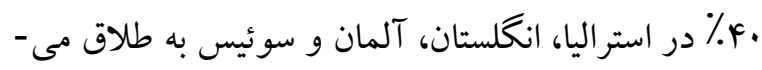

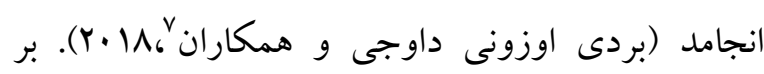
اساس آمار رسمى در ايران از هر ل..... مورد ازدواج، حدود · r. مورد به طلاق منجر مىشود (بهروز و

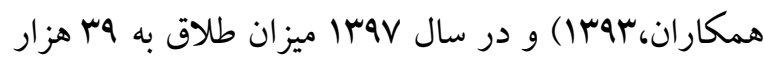
رسيده است (زارعيان و جابكى، جوسا) و ايران، جهارمين كشور جهان از نظر ميزان نسبت طلاق به ازدواج معرفى

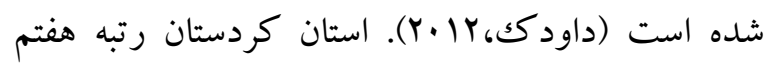
ميزان طلاق در كشور را دارد (آقايى،هوسا) و اين افزايش نرخ طلاق موجب نگر انى در ميان متخصصان در زمينه هاى مختلف شده است (محمدى و همكاران،

طلاق علاوه بر زن و شوهر بر فرزندان و اقتصاد جامعه

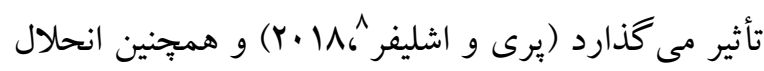
روابط زناشويى ييامدهاى مهمى براى سلامتى فرد و

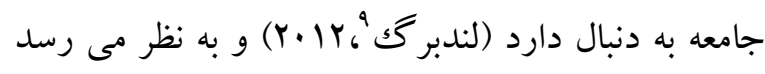
يكى از مهم ترين عوامل در شكل گيرى و تغيير شكل جامعه است. ماهيت بيجيده طلاق و تأثير آن بر مردان، زنان، كودكان و خانوادههاى آنان، طلاق را به عنوان عامل مهمى در سلامت روانى افراد و جامعه قرار مى دهد

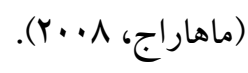

عوامل مختلفى مانند عوامل اقتصادى و اجتماعى، عوامل محيطى و زنتيكى، كيفيت ارتباط و تعهد به ازدواج و و رفتارهاى متضاد و مخرب و ويز كى هاى شخصيت در

6. Motataianu IR

7 - Berdi Ozouni-Davaji R, et al

${ }^{8}$ - Perry SL, Schleifer C

${ }^{9}$ - Lundberg $\mathrm{S}$

\section{مقدمه}

انسان در زندگیى خود مقاطع و مراحل حساسى را يشت

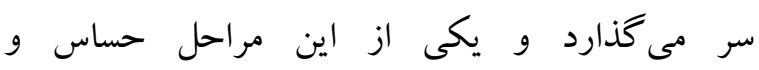

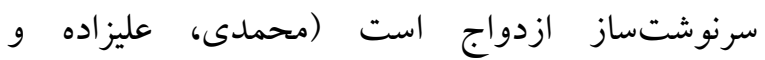
صداقت، (1) (Y). خانو اده يك نهاد اجتماعى است كه مرد و زن با هم زندگى را براى تحقق برخى از مسئوليتهاى اجتماعى و شخصى شروع مى كنند و علاوه بر تأمين نياز اساسى زيست شناختى به لذت جنسى از طريق يكك راه قابل قبول اجتماعى، سطح بالاترى از بلوغ شخصيت را به له له

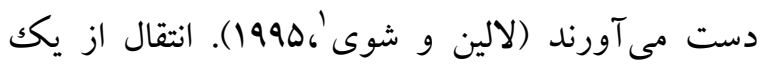
جامعه سنتى به مدرن مشكلات بالقوهاى مانند طلاق را

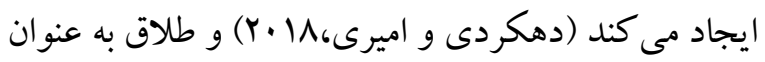
انحلال ازدواج تعريف مىشود كه در طى يكك روند قانونى زندكى زناشويى دو نفر پِيان مى يابد (ماهاراج؛

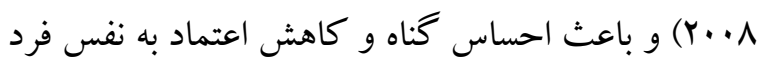

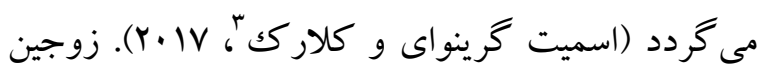
احساس مى كنند كه امنيت عاطفى آنها تهلديد مى شود و سرخوردگىى، احساس كناه، خشم و عزت نفس بايين را

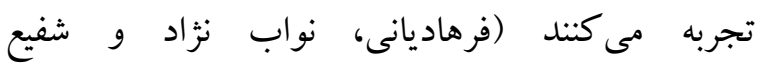

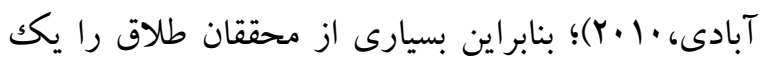

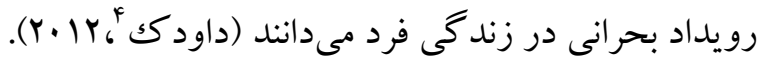
ختم زندگى زناشويى با كاهش سلامت، افزايش مرگك و مير، سطح بِيين رفاه ذهنى، سطوح بالاى افسردگى و و اضطراب و اختلال در عملكرد همراه است (كريستل و

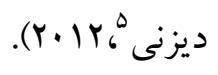




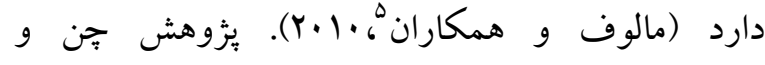

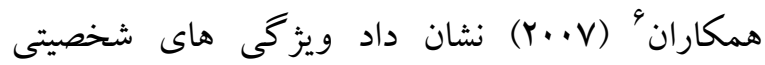
شريك زندكى مىتواند ساز گارى زوجين را بيش بينى نمايد. نتايج بزوهش براتى و همكاران (19 (Y) نيز به اين نتيجه منجر شد كه بين تيب شخصيتى A ل طلاق رابطه ى مثبت و معنادارى مشاهده كرديد. همجنين ليّن

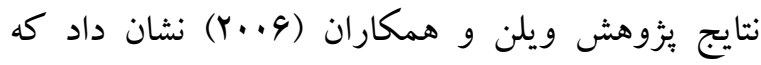
اختلالات شخصيت در افراد متقاضى طلاق بيشتر از جمعيت عادى است (ويلن و همكاران به نقل از حاج نايب، كودرزى و قاسمى، جمالى (Y Y Y (Y) در مقايسه اختلالات شخصيت در زوجين متقاضى طلاق با افراد عادى، نتايج نشان داد كه بين افراد متقاضى و غير متقاضى طلاق ارتباط معنىدارى در اختلالات شخصيت وجود دارد. همجنين نتايج يزوهش

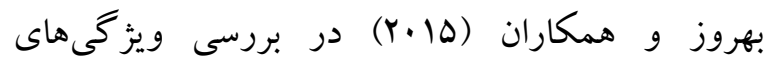
شخصيت در زوج هاى متقاضى طلاق و عادى، يافته ها

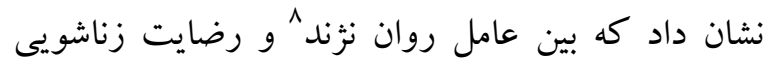

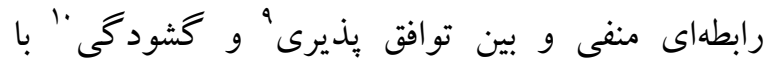
رضايت زناشويى رابطه مثبت وجود دارد و بين زوج هاى عادى و متقاضى طلاق از نظر ويزگى هاى شخصيت

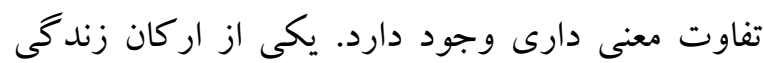
زناشويى موفق، سلامت روان زوجين است و اختلالات شخصيت از مباحث مهم روانيزشكى است كه به گونهاى آشكار مورد غفلت و بى توجهى قرار گرفته است (نايب و همكاران، شخصيت و طلاق در مطالعات مختلف مشخص شده اما

5- Malouff JM,et al

${ }^{6}$ - Chen Z,et al

7- Type A personality

${ }^{8}$ - Neuroticism

9 - Agreeableness

${ }^{10}$ - Openness
ظهور طلاق مؤثر هستند (شاكرى و همكاران،YF).Y.). شخصيت عبارت است از الكوى نسبتاً پِايدار صفات، كرايشها يا ويزّكى هايى كه تا اندازهاى به رفتار فرد دوام مىبخشد. به طور اختصاصىتر، شخصيت، از صفات يا كرايشهايى تشكيل مىشود كه به تفاوتهاى فردى در رفتار، ثبات رفتار در طول زمان و تداوم رفتار در

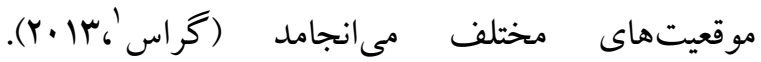
اختلالات شخصيت با الخوهاى ماندكارى ادراكى، ارتباط و تفكر درباره محيطى كه در طيف وسيعى از زمينه هاى اجتماعى و شخصى نمايش داده مى شوند، مشخص مى -

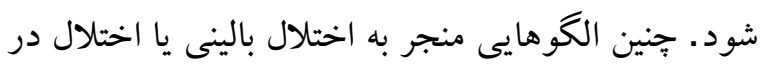

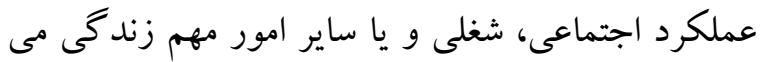

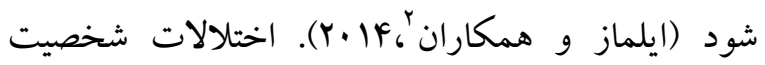
شايع و مزمن هستند و ميزان شيوع آنها در جامعه عمومى بين ·ل تا ·r درصد تخمين زده شده است (دونيوى،

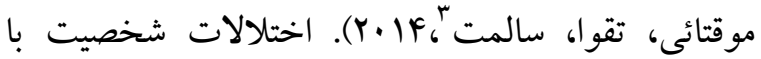
اختلال در عملكرد در حوزههاى مختلف بين فردى، از جمله روابط زناشويى همراه است. دشوارى تعامل با ديخران، ناتوانى در حفظ روابط صميمى يكى از ويز گیى هاى اصلى اكثر اشكال آسيب شناسى شخصيت است كه با افزايش قابل توجهى در احتمال درگيرى هاى عاشقانه و إنى

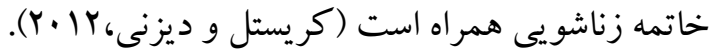

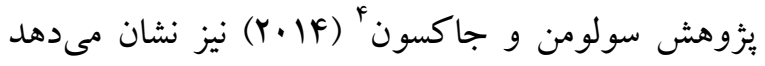

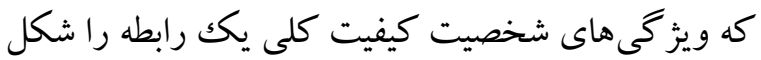
مى دهند كه به نوبه خود بر احتمال انحلال رابطه نيز تأثير مى گذارد و ارتباط زيادى بين ويز گى هاى شخصيت فرد و رضايت از رابطه و صميميت با شريك زندگى وجود

\footnotetext{
1. Grass MG

2. Yilmaz A,et al

${ }^{3}$ - Donyavi V, Moghtadaei K, Taghva A, Salamat M

${ }^{4}$ - Solomon BC, Jackson JJ
} 
منازل مراجعه و ويرسشنامه تكميل گرديد. غير متقاضيان طلاق از لحاظ سن، جنس و متغيرهاى اقتصادىاجتماعى و فردى با متقاضيان طلاق همسان سازى شدند.

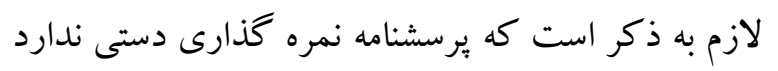
و توسط نرم افزار آناليز شد و نمره نهايى در هر مقياس

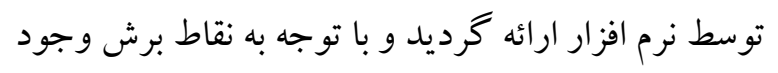
يا عدم وجود اختلال شخصيت در زوجين مشخص شد. با توجه به مطالعه قبلى (نوروز زاده، وها1) و با توجه به فرمول نمونه گيرى و با توجه به مقادير زير تعداد هه نفر

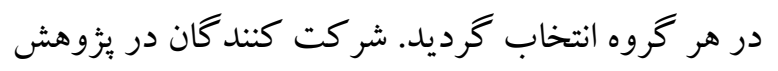
هزينه اى در قبال انجام تست برداخت نكردند و براى حفظ محرمانه بودن، اسامى افراد بر روى برسشنامه ها

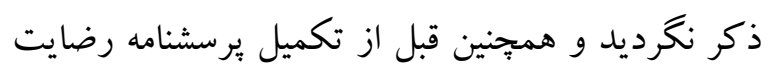
آكاهانه از زوجين اخذ شد.

$$
n \geq \frac{\left(z_{1-\alpha / 2}+Z_{1-\beta}\right)^{2}\left(\sigma_{1}^{2}+\sigma_{2}^{2} / r\right)}{\left(\mu_{1}-\mu_{2}\right)^{2}}
$$

ابزار

جهت جمع آورى اطلاعات از برسشنامه هاى دو قسمتى مشخصات دمو گرافيك (سن - جنسيت- تعداد سالهاى إن ازدواج- فرزند جندم خانواده بودن- شغل) و يرسشنامه اختلالات شخصيت ميلون III استفاده شد. برسشنامه جنل محوروى بالينى ميلون': يكى يرسشنامه خودسنج استاندارد شده است كه دامنه گسترده اي از ازئل اطلاعات مربوط به شخصيت را مى سنجد. اين برسشنامه براى بزرگكسالان بالاى \1 سال كه دست كم توانايى

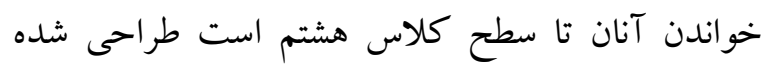
است (كراس،س| •Y). برسشنامه شامل بررسى شخصيت و
تعيين انواع اختلالات شخصيت رايج در جوامع مختلف مى تواند امكان برنامه ريزى و ارائه راهكارها را افزايش دهد. با توجه به اهميت و افزايش جشمخير طلاق در استان كردستان و همجينين اهميت وجود اختلالات شخصيت در اين امر مهم، بر آن شديم ميزان وجود اختلالات شخصيت و مقايسه ميزان آن در زوجين متقاضى و غير متقاضى را بررسى نماييم.

روش مطالعه حاضر مقطعى و از نوع على مقايسهاى بود و جامعه مورد مطالعه شامل كليه متقاضيان طلاق (زن و مرد) مراجعه كننده به مراكز مشاوره طلاق شهرستان سنندج در

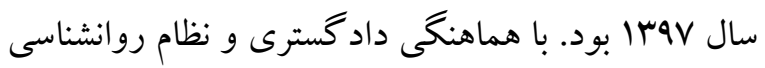

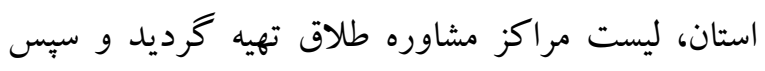

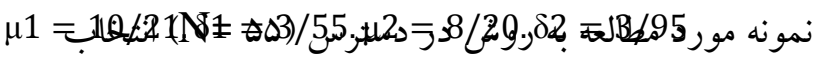
شد. معيارهاى ورود به ئزوهش شامل، متقاضى طلاق

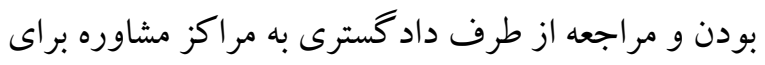
طلاق، سواد خواندن و نوشتن، عدم اعتياد، تحت درمان روانشناختى نبودن و تمايل به شركت در يزوهش بود و معيارهاى خروج شامل عدم تكميل تمامى سؤالات يرسش نامه در نظر گرفته شد. يرسشنامه ميلون براى زنان و مردان مراجعه كنندگان براى طلاق، در محل مركز مشاوره ارائه شد و بعد از تكميل زوجين توسط نرم افزار يرسشنامه جند محورى بالينى ميلون III آناليز صورت كرفت. گروه شاهد از بين زوجين غير متقاضى طلاق به روش خوشه اى جند مرحلهاى از مناطق جهار گانه شهرستان سنتدج انتخاب شدند. ابتدا سنندج به تجهار منطقه شمال، جنوب، شرق و غرب در نظر گرفته شده و سيس در هر منطقه به صورت تصادفى ساده به درب

\footnotetext{
${ }^{1}$ - Inventory Multiphasic Personality Minnesota(MCMI)
} 
واريانس يككطرفه استفاده و براى تمام آزمون ها سطح معنادارى برابر ه.٪ در نظر كرفته شد.

يافتهها

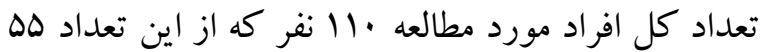
نفر افراد متقاضى طلاق و هله نفر هم افراد غير متقاضى طلاق بودند. تعداد هV نفر (r/Y نr/\%) زن و تعداد Y مرد بودند. در بين افراد مورد مطالعه تعداد نفر (19/1\%) از سطح درآمد كم، تعداد V9 نفر (199/1\%)

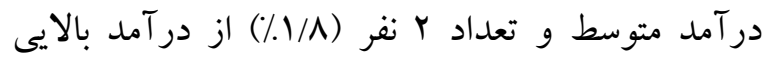
برخوردار بودند. تعداد \| نفر (F/9|4\%) داراى تحصيلات

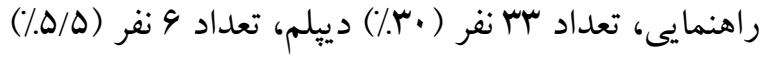
كاردانى، تعداد هץ نفر (ه/هr/\%) كارشناسى و تعداد نفر (9/1/\%) كارشناسى ارشد بودند. در بين نمونه هاى مورد مطالعه بيشترين تعداد YV نفر (Y/YY/\%) فرزند اول خانواده و كمترين تعداد ب نفر (Y/9/) فرزند ششم خانواده بودند. ميانگين سن افراد شركت داده شده در

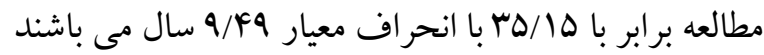
كمترين سن مشاهدهشه برابر با ل1 و و بيشترين وه سال

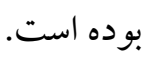

از بين ويز خىهاى دمو گرافيك مورد مطالعه فقط سطح تحصيلات بين افراد گروه متقاضى طلاق و افراد غير

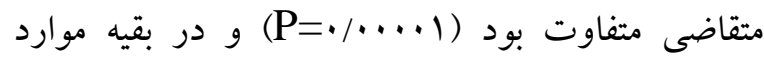
تفاوت معنى دارى بين دو گروه مورد مطالعه از نظر مشخصات دمو كرافيك وجود نداشت. براى مقايسه بين ميانگين سن در دو گروه افراد متقاضى و غير متقاضى طلاق از آزمون تى دو نمونه مستقل استفاده

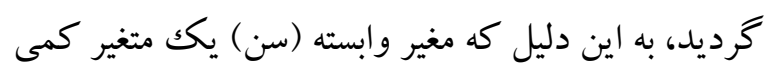

عوامل بالينى است (سانجز، آميوديا، جيمنزو

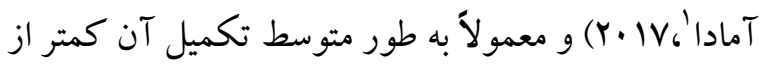

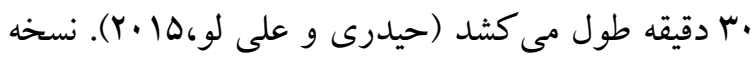
اصلى اين آزمون در سال 19VV توسط ميلون تدوين شد

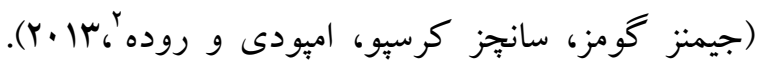
YF برسشنامه شامل IVD سؤال بله خير است و شامل مقياس بالينى و r مقياس تعديل كننده است (خرم) رضايى و دولت شاهى، · (Y. (Y). ميلون تصريح مى كند كه نمره هاى در دامنه VD-AF نشان مىدهند كه نشانگان يا الكو وجود دارد، در صورتى كه نمره هاى هم يا بالاتر

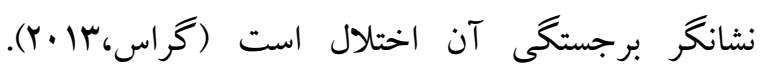

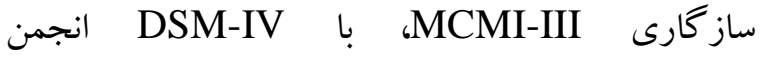
روانيزشكى آمريكا، قابل قبول است (مارلوَّو همكاران،

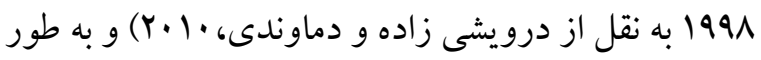
كسترده اى در ايالات متحده آمريكا و در بسيارى از كشورهاى ديخر براى ارزيابى روانيزشكى در انواع

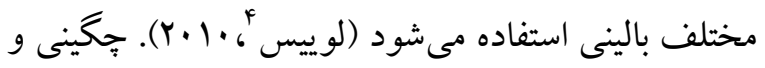

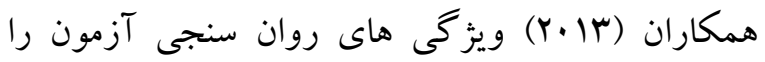
بررسى و تحليل داده ها نشان داد كه يايايى به روش

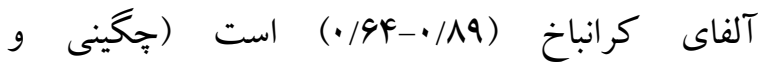
هوشمند، وM I). يُس از جمع آورى و وارد نمودن داده ها در نرم افزار SPSS نسخه آY، براى توصيف متغيرهاى كيفى از جداول و نمودارها (فراوانى و درصد) و براى متغيرهاى كمى از شاخص هاى مركزى و براكند إكى

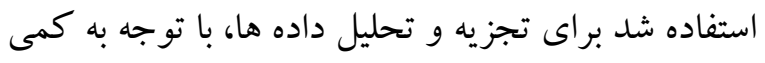
بودن متغير وابسته، از آزمون تى دو نمونه مستقل و آناليز

\footnotetext{
1- Sánchez G, Ampudia A, Jiménez F, Amado BG

² Jiménez-Gómez F, Sánchez-Crespo G, Ampudia-Rueda A

3 - Marlowe
}

4- Lewis JE 


$$
\text { با توزيع نرمال و متغير مستقل (كروه) يكك متغير كيفى دو بالته بودهاست. }
$$

\begin{tabular}{|c|c|c|c|c|c|}
\hline سطح معنى & آماره آزمون & انحراف معيار & ميانكين & كروه & متغير \\
\hline \multirow{2}{*}{$\cdot / \cdots \cdot \mid$} & \multirow{2}{*}{$-V / I F \Delta$} & $9 / 99$. & $r q / A r$ & متقاضى & \multirow[t]{2}{*}{ سن } \\
\hline & & $1 / 910$ & $F \cdot / \Delta V$ & غير متقاضى & \\
\hline
\end{tabular}

براى مقايسه افشاكرى، مطلوبيت و بدنمايى در دو گروه متقاضى طلاق و غير متقاضى از آزمون تى دو نمونه مستقل استفاده گرديد. به اين دليل كه مغير وابسته (سن) يكك متغير كمى با توزيع نرمال و متغير مستقل (كروه)

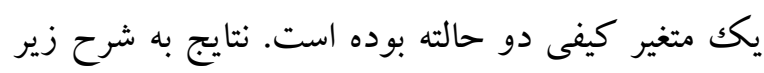

ميانگين سن در افراد متقاضى طلاق برابر با ra/Ar با انحراف معيار 9/99 سال و در گروه غير متقاضى طلاق برابر با F.OVV با انحراف معيار N/910 سال است نتايج آزمون تى مستقل نشان داد كه تفاوت معنى دارى بين كروه متقاضى و غير متقاضى طلاق از نظر ميانخين سن

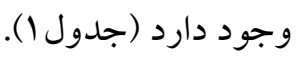

\begin{tabular}{|c|c|c|c|c|c|}
\hline سطح معنى & آماره آزمون & انحر اف معيار & ميانكين & كروه & متغير \\
\hline$\cdot / \cdots \wedge$ & Y/VID & $\begin{array}{l}\text { N/IVD } \\
r \cdot / \text { IVV }\end{array}$ & $\begin{array}{l}\text { GN/AD } \\
9 \cdot / 1 F\end{array}$ & غير متقاضى متقاضى & افشاكرى \\
\hline$\cdot / \cdot r$ & $-r / r \mid \Lambda$ & $\begin{array}{l}10 / 99 \\
1 V / Y F\end{array}$ & $\begin{array}{l}G K / F F \\
V H / \Delta D\end{array}$ & غير متقاضى متقاضى & مطلوبيت \\
\hline$\cdot / \cdots 1$ & $F / Y V I$ & $\begin{array}{l}Y F / Y Y \\
Y D / T Q\end{array}$ & $\begin{array}{l}\Delta \cdot / F r \\
r \cdot / \mu l\end{array}$ & غير متقاضى متقاضى & بدنمايى \\
\hline
\end{tabular}

رايج ترين الكو در بين شاخص هاى تغيير دهنده در گروه متقاضى طلاق افشاكرى و در گروه غير متقاضى طلاق مطلوبيت است. ماند جداول قبلى با توجه به اينكه متغير وابسته از نوع كمى با توزيع نرمال بوده است به همين دليل براى مقايسه ميانگين اين متغيرهاى كمى در سطوح متغير كيفى دو حالته از آزمون تى دو نمونه مستقل استفاده كرديد كه مهيد نتايج به شرح زير است:
با توجه به مقادير حاصل از آزمون تى مى توان نتيجه

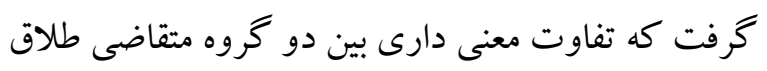
و غير متقاضى طلاق از نظر شاخصهاى تغيير دهنده وجود دارد. در افراد متقاضى طلاق شاخص بدنمايى و افشاكرى از ميانگين بالاترى نسبت به افراد غير متقاضى مشاهده شده است؛ ولى شاخص مطلوبيت در افراد متقاضى طلاق ميانگين يايين ترى نسبت به افراد غير

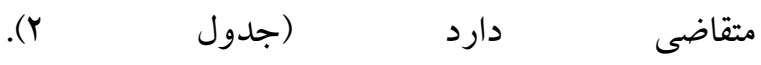


جدول r مقايسه الكوهاى شخصيت بالينى در دو كروه متقاضى و غير متقاضى طلاق

\begin{tabular}{|c|c|c|c|c|c|}
\hline سطح معنى & $\begin{array}{l}\text { آزماره } \\
\text { آمون }\end{array}$ & انحر اف معيار & ميانكين & كروه & متغير \\
\hline \multirow[t]{2}{*}{$\cdot / \cdots \Delta$} & $r / \Lambda \Lambda$ & $r Y / D I$ & एव/৭४ & متقاضى & اسكيزوئيد \\
\hline & & Tr/GF & TV/TD & غير متقاضى & \\
\hline \multirow[t]{2}{*}{$\cdot / \cdots \cdot 1$} & $r / 99 V$ & $19 / 1 r$ & $\mathrm{rq/v}$ & متقاضى & دورى گزين \\
\hline & & $r \cdot / \mu$ & TF/VD & غير متقاضى & \\
\hline \multirow[t]{2}{*}{.$/ \cdot 1$} & $r / Y 90$ & $r r / 90$ & $\Delta \Delta / \Delta \Lambda$ & متقاضى & افسردگى \\
\hline & & $r \Delta / F r$ & $F \cdot / r$. & غير متقاضى & \\
\hline \multirow[t]{2}{*}{$\cdot \cdots 1$} & $r / \Delta 9 \Lambda$ & $Y F / T D$ & $r 9 / .4$ & متقاضى & وابسته \\
\hline & & IN/AF & $r M / 10$ & غير متقاضى & \\
\hline \multirow[t]{2}{*}{$\cdot / \cdots 1$} & $-r / 990$ & $r \mu / l$. & $99 / 91$ & متقاضى & نمايشى \\
\hline & & $r 9 / 11$ & $\Lambda F / \mu$ & غير متقاضى & \\
\hline \multirow[t]{2}{*}{.1 .49} & $-r / \cdot 19$ & $r Y / I T$ & FY/GV & متقاضى & خودشيفته \\
\hline & & IV/VV & $\Delta \cdot / F$. & غير متقاضى & \\
\hline \multirow[t]{2}{*}{$\cdot / Q F V$} & $\cdot 19 \cdot 4$ & $I V / T F$ & YY/VI & متقاضى & ضد اجتماعى \\
\hline & & $10 / v 9$ & TF/GY & غير متقاضى & \\
\hline \multirow[t]{2}{*}{$\cdot / F \Delta 1$} & $\cdot / v \Delta \Delta$ & $1 N / 9 V$ & Rr/99 & متقاضى & ديكر آزار \\
\hline & & $1 N / 9 Y$ & rq/৭1 & غير متقاضى & \\
\hline \multirow[t]{2}{*}{. /AAF } & 1/M & YA/Al & Vr/G. & متقاضى & وسواسى \\
\hline & & $r \Delta / 19$ & $99 / \mathrm{VI}$ & غير متقاضى & \\
\hline \multirow[t]{2}{*}{$\cdot 1 \cdot \mathrm{YG}^{4}$} & r/YOY & $r q / 9 F$ & $\Delta 1 / \cdot r$ & متقاضى & منفى كرا \\
\hline & & rN/FMT & 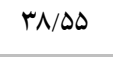 & غير متقاضى & \\
\hline \multirow[t]{2}{*}{.$/ \cdots 1$} & $r / F V$. & Yr/DI & $F r / Q \Delta$ & متقاضى & خود آزار \\
\hline & & $r \cdot / r q$ & ra/vQ & غير متقاضى & \\
\hline
\end{tabular}

با توجه به نتايج جدول فوق همه الكوهاى شخصيت بالينى با توجه به اينكه متغير وابسته از نوع كمى با توزيع نرمال

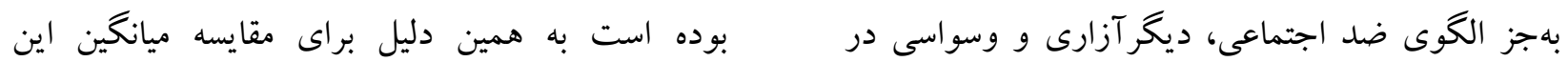
بين متقاضيان طلاق و غير متقاضيان داراى تفاوت متغيرهاى كمى در سطوح متغير كيفى دو حالته از آزمون

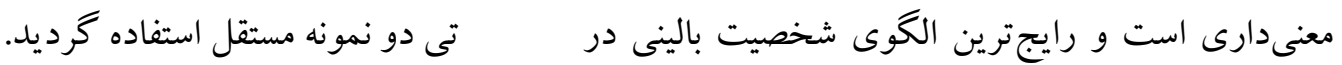
كروه متقاضى طلاق وسواسى و در گروه غير متقاضى براى مقايسه بين زير گروه هاى آسيب شناسى شديد در دو گروه مستقل از آزمون تى دو نمونه مستقل استفاده طلاق نمايشى است (جدول r). كرديد كه نتايج به شرح زير است: 


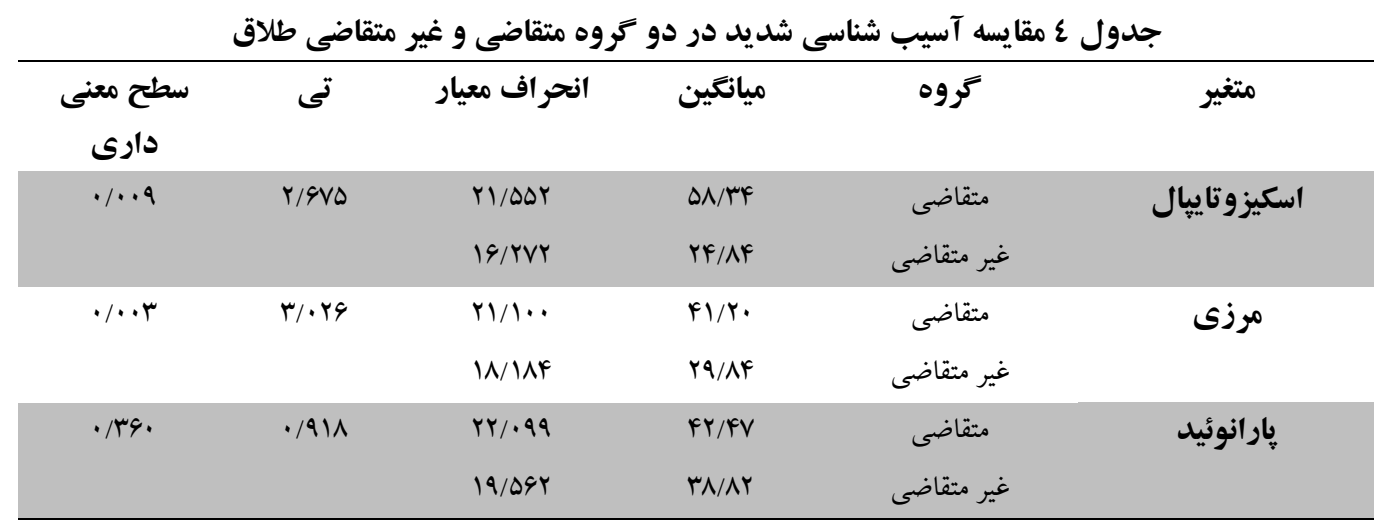

در گروه متقاضى طلاق و غير متقاضى طلاق پارانوييد

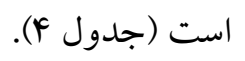

براى مقايسه بين زير گرووه هاى آسيب شناسى شديد در دو گروه مستقل از آزمون تى دو نمونه مستقل استفاده كرديد كه نتايج به شرح زير است. در هر جهار زير كروه ميانگين در گروه افراد متقاضى بيشتر از ميانخين در خروه غير متقاضى بوده است.
با توجه به مقادير حاصل از آزمون تى مى توان نتيجه

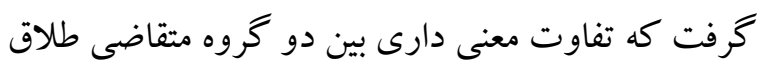
و غير متقاضى طلاق از نظر اسكيزوتايبال و مرزى وجود دارد. در افراد متقاضى طلاق اين دو شاخص از ميانخين مئع بالاترى نسبت به افراد غير متقاضى مشاهدهده است. براى شاخص بارانوئيد ميانخين افراد متقاضى طلاق بيشتر از افراد غير متقاضى است؛ ولى اين تفاوت از نظر آمارى معنى دار نيست. رايج ترين الكوى آسيب شناسى شديد

جدول 0 مقايسه نشانكان بالينى در دو كروه متقاضى و غير متقاضى طلاق

\begin{tabular}{|c|c|c|c|c|c|}
\hline سطح معنى & $\begin{array}{l}\text { آزماره } \\
\text { آزمون }\end{array}$ & انحر اف & ميانكين & كروه & متغير \\
\hline$\cdot / \cdot r$ & r/IVA & $\begin{array}{l}r \mid / q / r \\
r r / F V G\end{array}$ & $\begin{array}{l}r q / q 4 \\
r \Delta / A V\end{array}$ & غير متقاضى متقاضى & اختلال اضطرابى \\
\hline .1 .94 & l/Mr & $\begin{array}{l}r \Delta / \Delta A V \\
r I / F Y q\end{array}$ & $\begin{array}{l}r / / 99 \\
r \cdot / F q\end{array}$ & غير متقاضى متقى & اختلال شبه جسمى \\
\hline ./rYq &.$/ 94$. & $\begin{array}{l}\text { YQ/ATV } \\
\text { YF/MIV }\end{array}$ & $\begin{array}{l}r N / Y V \\
Y r / Q \Lambda\end{array}$ & غير متقاضى متقى & مانيك \\
\hline$\cdot / \cdots 1$ & $9 / \mathrm{TV}$ & $\begin{array}{l}\text { M/DIT } \\
\text { M/DrG }\end{array}$ & $\begin{array}{l}F q / r \Delta \\
r V / I I\end{array}$ & غير متقاضى متقى & افسرده خويى \\
\hline . /FAY & $\cdot / V r q$ & $\begin{array}{l}10 / \& 99 \\
1 F / 9 \wedge Y\end{array}$ & $\begin{array}{l}\text { IV/a9 } \\
10 / A r\end{array}$ & غير متقاضى متقى & وابستكى به الكل \\
\hline.$/ 949$ & $-\cdot / \cdot \wedge 1$ & $\begin{array}{l}\mid \Delta / \cdot \Delta \Delta \\
|r / \pi r|\end{array}$ & $\begin{array}{l}19 / 01 \\
19 / 1 .\end{array}$ & غير متقاضى متقى & وابستى به دارو \\
\hline.$/ \cdots 1$ & r/As. & $\begin{array}{l}\text { YF/RYQ } \\
\text { YY/WVI }\end{array}$ & $\begin{array}{l}M F / F F \\
\mid V / \cdot q\end{array}$ & غير متقاضى متقى & استرس پس از ضربه \\
\hline
\end{tabular}


براى مقايسه بين زير گروه هاى نشانگان شديد در دو كروه مستقل از آزمون تى دو نمونه مستقل استفاده گرديد كه نتايج به شرح زير است. در هر سه زير گروه ميانگين در گروه افراد متقاضى بيشتر از ميانگين در كروه لهره غير متقاضى بوده است.
تفاوت معنى دارى بين دو گروه متقاضى طلاق و غير متقاضى طلاق از نظر شاخص هاى اختلال اضطرابى، افسرده خويى و استرس بس از ضربه وجود دارد، در بقيه موارد تفاوت معنى دارى مشاهده نشده است و رايج ترين الكوى نشانگان بالينى در گروه متقاضى طلاق و غير متقاضى اختلال اضطر ابى است (جدوله ه).

\begin{tabular}{|c|c|c|c|c|c|}
\hline \multicolumn{6}{|c|}{ جدول 7 مقايسه نشانكان شديد در دو كروه متقاضى و غير متقاضى طلاق } \\
\hline سطح معنى & تى & انحر اف & ميانغين & كروه & متغير \\
\hline \multirow[t]{2}{*}{$\cdot / \cdots 1$} & F/YTr & $r \cdot / A r$ & $\notin q / \Delta \Delta$ & متقاضى & اختلال تفكر \\
\hline & & rI/A. & $\operatorname{rr} / A r$ & غير متقاضى & \\
\hline \multirow[t]{2}{*}{$.1 . .1$} & r/TYD & $r \Delta / 1 \Lambda$ & $F \cdot / \mu q$ & متقاضى & افسردكى اساسى \\
\hline & & rr/Mg & $r \Delta / \cdot F$ & غير متقاضى & \\
\hline \multirow[t]{2}{*}{$\%$ ro } & $r / T V r$ & $r F / l F$ & $\pi / 90$ & متقاضى & اختلال هذيانى \\
\hline & & $19 / v 9$ & $r \varphi /$. & غير متقاضى & \\
\hline
\end{tabular}

در زوجين متقاضى طلاق و زوجين غير متقاضى طلاق صورت گرفت و يافته هاى اين بيزوهش در راستاى يثزوهشهايى است كه بيانكر تفاوت اختلال شخصيت در متقاضيان طلاق و غير متقاضيان مىباشند. نتايج به دست آمده از يزوهش حاضر نشان داد كه در افراد متقاضى طلاق شاخص بدنمايى و افشاگرى از ميانگين بالاترى نسبت به افراد غير متقاضى مشاهده شده است؛ ولى شاخص مطلوبيت در افراد متقاضى طلاق ميانگين پيايين ترى نسبت به افراد غيرمتقاضى دارد و تفاوت در هر سه مقياس بين متقاضيان و غير متقاضيان طلاق معنىدار شد. همه الخوهاى شخصيت بالينى اسكيزوئيد، دورى گزين، افسردگى، وابسته، نمايشى،

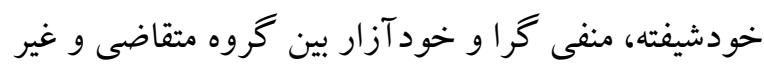
متقاضى طلاق داراى تفاوت معنىدارى بودند اما الخوى ضد اجتماعى، ديخر آزارى و وسواسى در بين متقاضيان
نتايج حاصل از مقايسه بين دو گرووه متقاضى و غير متقاضى طلاق از نظر شاخص نشانگان شديد مى توان استباط كرد كه ميانگين نمرات ابعاد اين شاخص در كروه متقاضى طلاق بيشتر از كروه غير متقاضى است و اين تفاوت از نظر آمارى معنى دار است (جدول 9).

عوامل مختلفى مىتوانند طلاق را به طرز قابل توجهى تحت تأثير قرار دهند و در اين ميان تمركز بر عوامل شخصيتى و روانى زوجين داراى اهميت فراوانى است

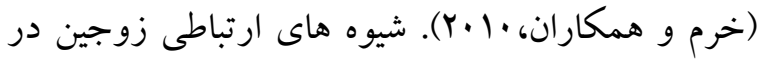
دركك، تفسير و ارزيابى يكديخر و رويدادهاى مربوط به رابطه آنها، تأثير قابل توجهى بر كيفيت روابط آنها دارد

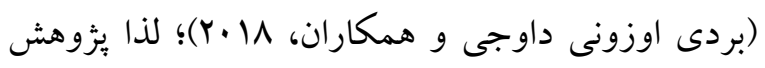
حاضر به منظور بررسى و مقايسه ميزان اختلال شخصيت 
(همهى اختلالات شامل اسكيزوئيد، اجتنابى، وابسته، نمايشى، ضداجتماعى، بِار انوئيد و مرزى به جز وسو اسى و

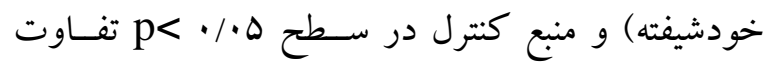
معنادار وجود دارد؛ اما در يزوهش حاضر مقياسهاى نمايشى، ضداجتماعى و خودشيفته نمرات افراد غير متقاضى طلاق بيشتر از متقاضيان است و حتى در مقياس ضداجتماعى اين تفاوت معنادار شده است. از دلايل احتمالى اين عدم همسويى را مىتوان بافت فرهنكى صنى استانها عنوان كرد و بيشنهاد مىشود در بئوهشهاى آتى دلايل آن بررسى گردد. با توجه به اينكه شخصيت نقش مهمى در رابطه زناشويى ايفا مى كند عوامل شخصيت زوج هاى طلاق نيز با زوج هايى كه ازدواج يايدار دارند، متفاوت هستند (لالين و شوى، 1990) و برخى از ويز گیىهاى شخصيت و اختلالات روانى تنشها. و تعارضات را بين زوجين افزايش مىدهد و تداوم زندكى زناشويى را مورد تهايد قرار مىدهد (شاهمر ادى،

. (1)

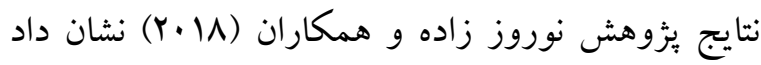
كه زنان و مردان متقاضى طلاق و غير متقاضى در سه

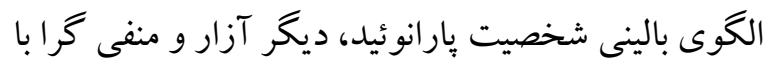
هم تفاوت معنىدارى داشتند و متغيرهاى شخصيتى اسكيزوئيد، دورى گزين، افسرده، نمايشى، ضد اجتماعى، خودآزار، اسكيزوتاييال و بِارانوئيد نسبت به ساير متغيرهاى شخصيتى با طلاق مرتبط بودند. در بيزوهش حاضر مقياسهاى تفاوت معنىدارى با هم داشتند و ضريب ارتباط متغيرها با طلاق بررسى نخرديد كه با توجه به تفاوت معنى دار شدن مقياسها در يزوهشهاى مختلف بيشنهاد مىشود در بروهشهاى آتى اين امر

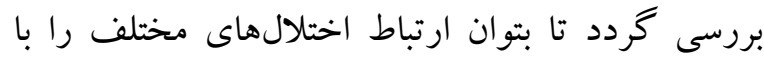

طلاق و غير متقاضيان داراى تفاوت معنىدارى نيست. ميانگين نمرات مقياسهاى نمايشى، خود شيفته و ضد اجتماعى در افراد غير متقاضى طلاق بيشتر از متقاضيان طلاق بود. تفاوت معنى دارى بين دو گروه متقاضى طلاق و غير متقاضى طلاق از نظر اسكيزوتايبال و مرزى وجود

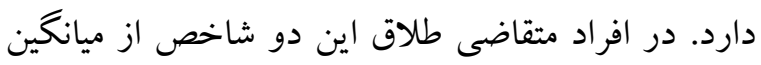
بالاترى نسبت به افراد غير متقاضى مشاهده شده است؛ اما براى شاخص بارانوئيد ميانگين افراد متقاضى طلاق بيشتر از افراد غير متقاضى است؛ ولى اين تفاوت از نظر آمارى معنى دار نمىباشد. تفاوت معنىدارى بين دو گروه متقاضى طلاق و غير متقاضى طلاق از نظر شاخص هاى اختلال اضطرابى، افسرده خويى و استرس يس از ضربه

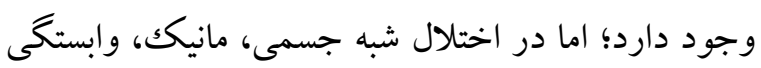
به الكل و وابستخى به دارو تفاوت معنىدارى مشاهده نشده است و نمرات متقاضيان طلاق در كل مقياسهاى نشانگان بالينى بيشتر از گروه غير متقاضى طلاق بود. نتايج يثزوهش حاضر نيز نشان داد كه ميانگين نمرات اختلال تفكر، افسردگى اساسى و اختلال هذيانى در كروه لتره متقاضى طلاق بيشتر از خروه غير متقاضى است و اين تفاوت از نظر آمارى معنىدار است. بيشترين ميانگين (AF/r)

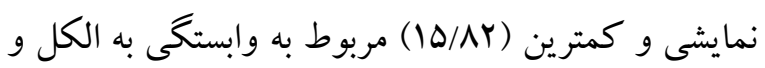
در افراد متقاضى طلاق بيشترين ميانخين مربوط به اختلال

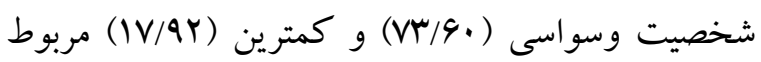
به وابستخى به الكل به دست آمده است.

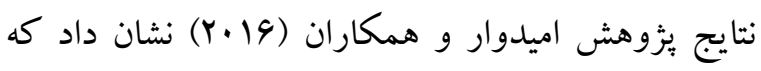
بين زوجهاى متقاضى طلاق و زوجهاى عادى از نظر

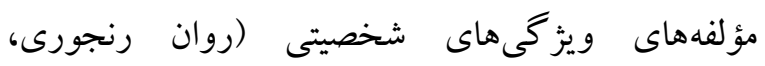

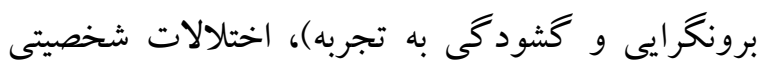


افزايش آمار طلاق در كشور ما، اين مطالعات شروع تلاش هاى متمركز براى توسعه درمانهاى زناشويى در آغاز شكايت در اختلافات زناشويى است و كاركنان قضايى و روانشناسان در اين رابطه با مشكلات روانى و جنبه هاى شخصيت مراجعه كنند كان خود آكاه و ور اقدامات لازم را در اين زمينه در نظر گيرند (لالين و

شوى، (1990).

تعداد سؤالات زياد برسشنامه و تعداد كم زوجين يكى از محدوديتهاى عمده در اين هيزوهش بود. با توجه به اينكه براى حفظ رازدارى اسامى بر روى برسشنامه درج نكرديد امكان بررسى وجود اختلال در هر زوج مقدور نبود و با توجه به اينكه برخى اختلالات شخصيت احتمال طلاق را افزايش مىدهد بيشنهاد مىشود در بزّوهش هاى آتى با حفظ رازدارى مشخص شود احتمال طلاق در بين كدام اختلالات بيشتر است و مردان و زنان هر كدام بيشتر جه اختلالى را دارا هستند و اينكه آيا فرزند جندم خانواده بودن تأثيرى بر ميزان طلاق دارد و بررسى گردد ميزان طلاق در كدام فرزندان بيشتر است.

\section{نتيجه كيرى}

با توجه به نتايج، بثزوهش حاضر نشان داد ميانكين خرده مقياسهاى شخصيت در كروه متقاضى طلاق بيشتر و

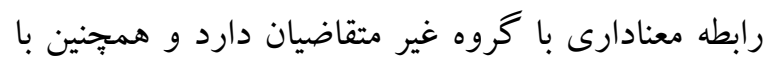
توجه به تأثير زياد ويز گى هاى شخصيتى بر همبستخى خانواده و تصميم آنان به طلاق، لزوم انجام تستهاى شخصيتى قبل از ازدواج براى زوجين و دوره هاى آموزشى براى افزايش آكاهى و درمانهاى مناسب روانشناختى در نظر گرفته شود.

سياسگز ارى
طلاق سنجيد. همجنين نتايج يزوهش اميرى و همكاران

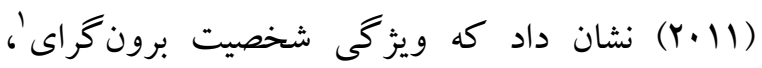

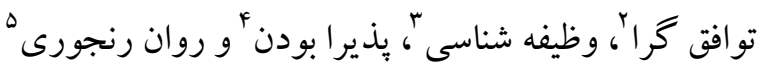
رابطه معنى دارى با رضايت زناشويى دارد. در يُوهش حاضر ضر ايب بيش بينى مقياسها محاسبه نشده است كه بيشنهاد مى شود با توجه به اهميت نقش بيش بينى صفات شخصيت در طلاق در يزٔوهش هاى آتى اين مسئله مدنظر قرار گيرد.

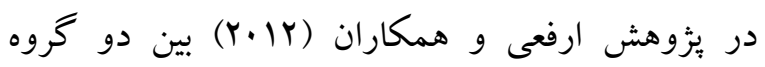
متقاضيان طلاق و غير متقاضيان در مؤلفههاى اسكيزوئيد،

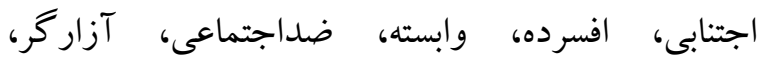

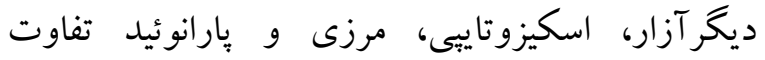

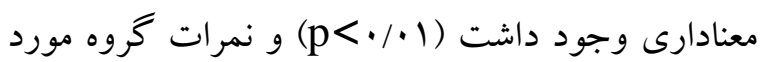
بيشتر بود؛ اما در مؤلفهاى خودشيفتگى، وسواسى -

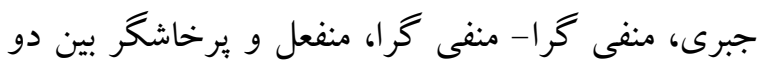
كروه تفاوت معنى دارى وجود نداشت (آريه - موسوى كارداجى فوروسقه و غليظه، (1) (Y). نتايج يثوهش حاضر در مقياسهاى اسكيزوئيد، افسرده، اسكيزوتاييى، وابسته، بارانوئيد و وسواسى با بزوهش حاضر همسو و در خرده مقياسهاى ضد اجتماعى، ديخر آزار، مرزى، خودشيفته و منفى گرا با بزوهش فوق غير همسو است. با توجه به عدم همسويى برخى مقياس ها در بررسى يزوهش هاى مختلف بيشنهاد مى گردد در يزٔوهشهاى آتى دلايل اين عدم

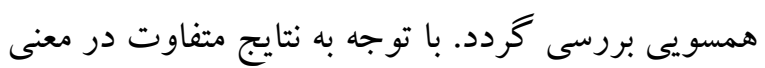
دار شدن متغيرهاى اختلال شخصيت در زوجين در يزّوهش حاضر و يزوهشهاى همسو و غير همسو، بررسى

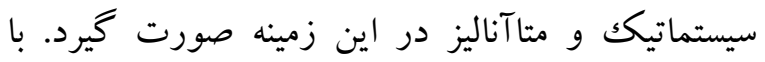

\footnotetext{
1. Extraversi

${ }^{2}$ - Agreeableness

3 - Conscientiousness

4 - Openness

5 - Neuroticism
} 
divorce among divorce-applicant couples. Journal of Research \& Health.8(1).21-31.

Byrami M, Gamahi M. (2011). Comparison of Cluster C Personality Disorders in Divorced Couples with Normal People. Journal of Woman and Family Studies. 4(14),1390-101.(In Persian)

Chen Z, Tanaka N, Uji M, Hiramura H, Shikai N, Fujihara S, et al. (2007). The role of personalities in the marital adjustment of Japanese couples. Social Behavior and Personality: an intemational journal.35(4),561572.

Chgini M, Hoshmand. (2013). The Psychometric Properties of the Millon Multiple Clinical Questionnaire. Joumal of Advanced Psychological Research.8(19),137-64(In Persian).

Donyavi V, Moghtadaei K, Taghva A, Salamat M. (2014). Relationship of personality disorders with suicidal-tendencies in a group of military soldiers. Quarterly physician and nurse in razm3(2),101-108.

Dudak A. (2012). The Selected Aspects Of Education Pursued By Divorced Fathers. Procedia-Social and Behavioral Sciences.55,910-614.

Farghadani A, Navabinejad S, Shafiabady A. (2010). Designing a model based on mindfulness, nonexistential resistance to life and sociability focusing on search for meaning in life in divorced women. Procedia-Social and Behavioral Sciences.5,1650-1664.

Grass MG. (2013). Psychosensory Guide1, editor. Tehran: Pasha Sharifi Nikkhoo Mohammad Reza.

Hagnayeb Z, Godarzi A, Gasimi M. (2015). The relationship between personality disorders and personality dimensions in divorce applicants. International Conference on Humanities, Psychology and Social Sciences. (In Persian)

Heidari S, Aliloo MM. (2015). Comparative Evaluation of Cognitive Emotion Regulation between 'B' Personality Disorders and Normal Persons.Procedia-Social and Behavioral Sciences.185,54-60.

Jafarian Dehkordi, Amiri M. (2018). Divorce: An International Multi- dimensional Challenge

$$
\begin{aligned}
& \text { اين مقاله حاصل طرح تحقيقاتى مصوب معاونت بزوهشى } \\
& \text { دانشگاه علوم يزشكى و خدمات بهداشتى درمانى دانشگاه }
\end{aligned}
$$

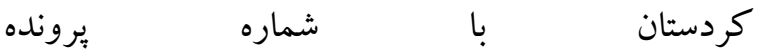

$$
\begin{aligned}
& \text { IIR.MUK.REC.1397.216.ست. بدين وسيله مراتب } \\
& \text { قدردانى و سياس خود را از كليه افرادى كه بِاسخگ } \\
& \text { يرسشنامه ها بودند اعلام مى نماييم و اميد است با توجه به } \\
& \text { نقش مهم و تأثير گذار مسائل روانشناختى، نتايج اين } \\
& \text { يثزوهش باعث آكاهى بيشتر و كاهش ميزان طلاق در } \\
& \text { جامعه گردد. }
\end{aligned}
$$

\section{References}

Amidvar Y. (2015). Comparison of Personality Traits, Personality Disorders, and Marital Control Source in Normal and Divorce Applicants. Thesis. (In Persian)

Amiri M, Farhoodi F, Abdolvand N, Bidakhavidi AR. (2011). A study of the relationship between Big-five personality traits and communication styles with marital satisfaction of mamied students majoring in public universities of Tehran. Procedia-Social and Behavioral Sciences,30,685-689.

Arphee AA, Mousavi S, Karadaghi G, forosqe M, Gholizadeh H. (2011). Comparison of personality disorder profile of women in divorce women with unmaried women in divorce in Tabriz city. Annual Congress of Iranian Psychiatric Association,28.

Barati, Barati S, Mosavi M. (2015). Personality Type and Divorce in Women. Contemporary Psychology.215,3-10.(In Persian).

Behroz B, Mohamadi F, Aliabadi SH, Kagbaf M, Hadarizadi N, Bhroz B. (2014). Comparison of Attributes and Attribution Styles in Normal and Divorced CoupleS. Knowledge and Research in Applied Psychology. 15(1),5261.(In Persian)

Berdi Ozouni-Davaji R, Farahbakhsh K, Esmaeily M, Kazemi F.(2018). Effect of couple's schema therapy in decreasing couples' tendency to 
Saleh. Intemational Joumal of Epidemiologic Research.5(2),64-66.

Jiménez-Gómez F, Sánchez-Crespo G, AmpudiaRueda A. (2013). Is there a social desirability scale in the MMPI-2-RF? Clínica $y$ salud.24(3),161-168.

Khorram N, Resaei O, Dolatshahi B. (2010). Comparison between personality profiles of the parents with schizophrenic offspring and normal parents based on MCMI-III. ProcediaSocial and Behavioral Sciences.5,901-904.

Krystle L, Disney YW, Thomas FO. (2012). Personality Disorder Symptoms Are Differentially Related to Divorce Frequency. J Fam Psychol.26(6),959-965.

Lalit b, shiv g. (1995). psychiatric morbidity and personality profile in divorce seeking couples. Indian J Psychiat.37(4),179-182.

Lewis JE. (2010). The Brazilian-Portuguese MCMIIII:Diagnostic validity of the alcohol dependence and drug dependence scales.

Lundberg S. (2012). Personality and marital surplus. IZA Journal of Labor Economics.3(1),1.

Maharaj SB. (2008). Personality profiles in the $16 \mathrm{PF}$ correlated with measures of distress in the Fisher's Divorce Adjustment Scale in divorced men. A dissertation submitted to the Faculty of Humanities, University of the Witwatersrand, Johannesburg in partial fulfillment of the requirements for the Degree of Master of Arts in Clinical Psychology.2-10.

Malouff JM, Thorsteinsson EB, Schutte NS, Bhullar N, Rooke SE. (2010). The five-factor model of personality and relationship satisfaction of intimate partners: A meta-analysis. Journal of Research in Personality.44(1),124-127.

Mohamadi M. (2016). Kurdistan's seventh divorce in the country / Over 10,000 marriages registered.Mehr News Agency. https://www.mehmews.com/news/3854014(I nPersian)

Mohammadi R, Alizadeh K, Sedaghat M.(2011).Need for cognition and problem solving styles in divorce applicant couples and normal couples. Procedia- Social and Behavioral Sciences, 30,894-898.
Motataianu IR.(2015).The Relation between Anger and Emotional Synchronization in Children from Divorced Families. Procedia-Social and Behavioral Sciences.203,158-162.

Noroz zadi V.(2017).Comparison of Personality Disorders of Divorce Applicant Couples Referred to Family Court in Comparison with Non-Applicant Persons. The first conference of social sciences, humanities education and psychology.(In Persian)

Perry SL, Schleifer C.(2018).Till pom do us part? A longitudinal examination of pomography use and divorce. The Joumal of Sex Research.55(3),284-296.

Sánchez G, Ampudia A, Jiménez F, Amado BG.(2017).Contrasting the efficacy of the MMPI-2-RF ovemeporting scales in the detection of malingering.The European Journal of Psychology Applied to Legal Context.9(2),51-56.

Shakerian A,Nazari A-M, Masoomi M, Ebrahimi P, Danai S.(2014).Inspecting the relationship between sexual satisfaction and marital problems of divorce-asking women in Sanandaj City family courts. Procedia-Social and Behavioral Sciences.114,327-333.

Shahmoradi S(2016).Divorce predictors based on personality traits, mental disorders, and demographic characteristics. Women and families.11(35),61-80.(In Persian)

Smith-Greenaway E,Clark S.(2017).Variation in the link between parental divorce and children's health disadvantage in low and high divorce settings. SSM-population health.3,473-486.

Solomon BC, Jackson JJ.(2014).Why do personality traits predict divorce? Multiple pathways through satisfaction. Joumal of Personality and Social Psychology.106(6),978.

Y1lmaz A, Cumurcu BE, Etikan I, Hasbek E, Donuk S.(2014).The effect of personality disorders on asthma severity and quality of life. Iranian Journal of Allergy ,Asthma and Immunology.13(1),47-54.

Zariyan M,CHboki A.(2017).Social Causes of Divorce in Women and Solutions.Second International 
Congress on the Role of Women in Family and Community Health.347-53.(In Persian)

Zadeh MD, Damavandi AJ. (2010). The incidence of personality disorders among substance dependents and non-addicted psychiatric clients. Procedia- Social and Behavioral Sciences .5,781-784. 